\title{
Procurement Bidding with Restrictions
}

\author{
Ganesh Iyer* Amit Pazgal ${ }^{\dagger}$
}

June 2007

*Haas School of Business, University of California at Berkeley, Berkeley, CA 94720-1900 giyer@haas.berkeley.edu.

${ }^{\dagger}$ Jesse H. Jones Graduate School of Management, Rice University, Houston, TX. pazgal@rice.edu 


\title{
Procurement Bidding with Restrictions
}

\begin{abstract}
In many procurement situations with simultaneously offered projects, firms face participation restrictions and can bid only on a subset of the projects. This phenomenon is prevalent in a variety of observed situations such as bidding for private label supplies, business to business procurement or government projects. We show that for the case of $n$ bidding firms where each is restricted to bid on a subset of the offered projects, there exists a symmetric equilibrium in which each bidder has a positive expected equilibrium profit. Prices are bounded away from marginal costs even if all the bidders are homogenous. this results from the fact that there is a positive probability that each firm will find itself in the position of being the sole bidder on a project. While the equilibrium probability of bidding on a project increases with its value, it is interesting to note that the bidding probability on the projects approaches an equiprobable one as the number of bidding firms increases.

We find that the equilibrium profits decrease as firms are able to bid on more of the available projects. In contrast, bidder commitment to bid on specific projects increases the equilibrium profits of all firms. We also examine the effect of heterogeneity on equilibrium profits. Greater heterogeneity in the project valuations leads to lower firm profits. On the other hand, heterogeneity among bidders in terms of the number of projects that they are constrained to bid on leads to greater profits for the firms that can bid on more projects (regardless of the mix of the firms in the industry.) Finally, we analyze the effect of uncertainty in project valuations and show greater uncertainty in project valuations (as represented by a mean preserving spread) decreases the equilibrium profits. We conclude with an empirical analysis of bidding behavior that tests the predictions of the theory. We find that the probability of bidding on a particular project is increasing in its value, decreasing in the other projects values and decreasing in the number of bidding subjects. Furthermore, the value of the bids on a project increase with its valuation and decrease with the total number of bidders.
\end{abstract}

Keywords: Bidding, Pricing Strategy, Procurement Strategy, Bertrand Paradox, Game Theory. 


\section{Introduction}

Many states award their construction projects to the lowest bidder in a sealed bid auction. For example, each month the state of Georgia invites bids on a large number of construction projects which the state is committed to deploy immediately after the bids. The department of transportation for the state releases a bimonthly summary of bidding results for the projects offered in the past couple of months. ${ }^{1}$ For example, for the projects offered by the state in June/July 2005 sealed bids were submitted by interested contractors and the results for 78 projects were announced on the 22nd of July. From the information presented it can be easily noticed that the majority of the construction firms bid on a single project or at most on two projects. ${ }^{2}$ This is because each firm is constrained either by resources or by the tight project time line that is demanded by the government and can hope to complete only one or at most two projects at the same time. Since the auctions for the projects are conducted simultaneously, any given firm must carefully analyze and determine which projects it should bid on and the precise amount of the bid.

A similar situation is encountered by baby formula manufacturers. States provide baby formula to their needy population via the Women Infants Children (WIC) program. Each year the states choose a preferred supplier via an auction. The manufacturer that offers the lowest per unit price in an auction usually wins the contract for the entire year. Because the public procurement auctions by all the states are held almost simultaneously, and because delivery requirements of the states are stringent, even large manufacturers such as Abbott-Ross are hard pressed to supply multiple states at the same time. ${ }^{3}$ This in effect leads to a simultaneous bidding environment where firms are constrained to bid on supplying to only some of the available states.

A third example is provided by the practice of large manufacturers of baked products who act as third-party suppliers of private label baking goods to supermarket chains. They prefer for all their private label bidding to be done prior to the revelation of any provider for any baking project. Consequently, they insist on having all their bidding to become suppliers to be done at the same time for all prospective clients. The public justification for this practice is the need to plan production in advance. ${ }^{4}$ A different motivation though could be to ensure that no single manufacturer has open capacity to serve the entire private label demand.

We investigate the optimal bidding strategies for participants facing constraints which restrict

\footnotetext{
${ }^{1}$ See http://www.dot.state.ga.us/dot/construction/contractsadm/index.shtml

${ }^{2}$ There were 52 bidding firms out of which 35 bid only on one project and 6 bid on two projects.

${ }^{3}$ See "WIC and the Retail Price of Infant Formula" USDA, May 2004 report.

${ }^{4}$ In private conversation with a large Midwestern manufacturer of bread we found out that the bidders are aware of the added benefit of higher prices generated when all the auctions are simultaneous.
} 
the number of auctions/projects they can participate in. We analyze environments in which participants are limited to bidding only on a strict subset of the simultaneously available projects. Specifically, we investigate a market where demand consists of buyers soliciting bids from potential suppliers for the completion of their projects. The bids are offered simultaneously via a sealed bid auction mechanism and the projects are awarded to the lowest bidder.

We begin by analyzing the symmetric equilibrium for the case of $n$ bidding firms each can bid on exactly one of $k$ simultaneously offered projects. We show the existence of a completely mixed equilibrium in which bidders randomly choose a project to bid upon and then bid according to a continuous cumulative distribution function. The main finding is that each bidder can have a positive equilibrium expected profits no matter how many firms enter the market. In fact, as long as the number of bidders are not too large compared to the number of projects there cannot exist a zero-profit equilibrium for the bidding firms. All the bidders are homogenous and the expected number of bidders on each project in equilibrium is positive. Yet, we find equilibrium prices to be bounded away from marginal costs. The intuition for the departure from marginal cost pricing lies in the fact that in equilibrium each firm has a strictly positive probability of finding itself in the position of being the sole bidder on the project. This provides a rationale for the behavior of private label manufacturers (other than better production planning) and to the resistance to their practice by supermarket chains.

As expected, the probability of bidding and the expected bid value on a high value project is higher than that on a lower value project, and depends of the ratio of the values. But perhaps the more interesting point is that as the number of bidding firms increases the probability of bidding on any project converges to $\frac{1}{k}$, irrespective of its value. Thus as the number of bidding firms increases all projects becomes similar in terms of attracting any given bidder. We show that the profit of each firm as well as their sum total profits decrease with number of firms.

We analyze the more general case in which the restrictions on bidding are relaxed and where each bidding firm can bid on more than one project. As the bidding firms are able to bid on more of the available projects the intensity of competition among the bidders increases and the equilibrium profits decrease. We also show that greater heterogeneity in the values of the projects as represented by a greater spread in project values leads to more intense competition among the bidders and lower equilibrium profits. Introducing heterogeneity among bidders in terms of the number of projects that they are constrained to bid on leads to the next result. Firms that have less severe restrictions and can bid on more projects achieve greater equilibrium profits regardless 
of the mix of the firms in the industry.

We extend the model to allow for the impact of bidder pre-commitment to bid on pre-specified projects. For example, in the construction industry many counties have a local bidding firm which would always bid on projects in the specific county. We show that in the commitment equilibrium with a guaranteed bidder for each project, competition is less intense and all firms get higher expected profits. Indeed this case is equivalent to the standard case but with one less firm. Finally, we research the effect of uncertainty in project valuations and show greater uncertainty in project valuations (as represented by a mean preserving spread) decreases the equilibrium profits to all firms.

We conclude the paper by presenting an empirical analysis of the bidding behavior in a simultaneous auction environment simulated in a computer controlled lab experiment in which subjects faced real monetary incentives. We find that the probability of bidding on the high value project is increasing in its value, decreasing in the value of the low value project, and decreasing in the number of bidding subjects. We show that the average (or median) bid for a high value project is higher than that for a low value project (significant at the $p=0.01$ level). Conditional on bidding on a specific project the participants bid value was increasing in the seller's willingness to pay and decreasing in the number of potential bidding firms. We also confirm the theoretical finding that the lowest support of the bid distribution is the same regardless of the project valuations.

The paper proceeds as follows. Section 1.1 describes the relevant literature. Section 2 describes and solves the main model while Section 3 extends the results to allow for bidder commitments and valuation uncertainty. The empirical finding are discussed in section 4 . and finally, Section 5 concludes.

\subsection{Relevant Literature}

This paper complements two different research streams: i) the auction literature that deals with simultaneous auctions and bidders that face some exogenous constraints, ii) the literature on ways to resolve the zero profit price competition equilibrium (Bertrand paradox.) Below we discuss closely related papers in both research streams.

Most of the existing literature on auction with bidding constraints deals with auctions where the highest bid wins and bidders face liquidity or budget constraints. In contrast, our paper investigates the role of the restrictions on the number of auctions a bidder can participate in. Engelbrecht-Wiggans and Webber (1979) show the existence of mixed strategy bidding equilibrium in an environment with $n$ simultaneous first price auctions, where bidders face a common budget 
constraint that can be allocated to at most two auctions. Palfrey (1980) examines multiple simultaneous first price auctions among bidders who have a common budget constraint. The paper analyzes the existence of pure bidding strategies and the impact of a seller's reservation price on these strategies. ${ }^{5}$

Edgeworth (1925) was the first to introduce the role of capacity constraints as a potential resolution to the Bertrand paradox in markets for homogeneous goods. Levitan and Shubik (1972) formalized his arguments in the context of a duopoly facing a linear demand function. Kreps and Scheinkman (1983) analyze two firms that invest in capacities and then compete in prices with constant marginal cost up to capacity and an arbitrarily large marginal cost above capacity. They show that the Cournot outcome is the unique Subgame Perfect Equilibrium of their pricing game. Harrington (1989) shows that the Bertrand paradox outcome is the unique equilibrium outcome only when firms produce at constant marginal cost, market demand is bounded, continuous, downward sloping, and consumers have a finite willingness to pay. This points the way to resolutions to the Bertrand paradox that do not rely on constraints. For example Baye and Morgan (2002) show that when monopoly profits are unbounded or when demand or costs are discontinuous positive profits can arise in an equilibrium of a homogeneous product price competition.

\section{The Model}

Consider an environment where demand consists of buyers soliciting bids from potential suppliers for the completion of their projects. There are $n \geq 2$ symmetric risk neutral firms (bidders) competing for offered projects in a first price sealed bid format. Buyers (for example, the state of Georgia) put the projects up for bid and their reservation value (maximum willingness to pay) for each of these projects is common knowledge. Let the number of projects that are simultaneously available for bid be $k$. Each project is awarded the lowest bidding firm provided that the bid is below the reservation value. We further assume that the marginal cost of undertaking each of these projects is the same across projects and firms and is less than the reservation value for each project. Without loss of generality assume that the cost of completing the projects, $c$, is equal to zero. This is equivalent to looking only at the difference between the willingness to pay and the

\footnotetext{
${ }^{5}$ More recently asymmetric information has been introduced in the context of budget constraints. Che and Gale (1998) analyze expected revenue and efficiency of single auctions when buyers have private information about their valuations and their budget constraint. Benoit and Krishna (2001) present a seller of two objects facing a group of bidders with common values for the objects. they show that in the presence of budget constraint sequential auctions yield higher revenue than simultaneous ascending auctions if the discrepancy in the values of the objects is large, or if there are significant complementarities.
} 
cost of completion. All participants know of the common value of the project and if all were to bid on a single project the unique equilibrium would entail bidding at the marginal cost of completion. The competitive environment is such that all projects open for bids simultaneously.

The purpose of the analysis is to investigate the effect of restrictions on the strategy of bidders. Denote by $m$ the number of projects that a bidding firm can bid on. Bidder strategies are restricted in that they can bid on only a subset of the potential projects and therefore $m<k$. We first begin with the analysis in which the bidders are restricted to bid on only one of the potential projects $(m=1)$. Thereafter we generalize the analysis to the case in which the restrictions on bidding are relaxed so that the firms can bid on multiple $(m<k)$ projects.

\subsection{The Case of $k$ Projects and $n$ Firms, each Bidding on $m=1$}

Consider the general case of $k \geq 2$ different projects characterized by maximum willingness to pay of $V_{1} \geq V_{2} \geq \cdots \geq V_{k}$ that are offered simultaneously to the $n$ bidding firms. Denote an action plan (or strategy) for firm $i$ by $S_{i}=\left(\left(q_{1 i}, F_{1 i}(b)\right),\left(q_{2 i}, F_{2 i}(b)\right), \cdots,\left(q_{k i}, F_{k i}(b)\right)\right)$, where $q_{j i}$ denotes the probability that firm $i \in\{1,2, \cdots, n\}$ bids on project $j \in\{1,2, \cdots, k\}$ and $F_{j i}(b)$ is the cumulative distribution function over the potential bid values. In other words it is the probability that firm $i$ bids below $b$ conditional on it bidding on project $j$. We further require that a firm will indeed bid on one project i.e., $q_{1 i}+q_{2 i}+\cdots+q_{k i}=1$ for every firm $i$.

Denote by $\Pi_{j}\left(S_{i} \mid S_{-i}\right)$ the expected profit of firm $i$ when it uses strategy $S_{i}$ and its competitors use strategy $S_{-i}$. Then a set of strategies $S^{*}=\left(S_{1}^{*}, S_{2}^{*}, \cdots, S_{n}^{*}\right)$ constitutes a Nash equilibrium if for every firm $i=1, \cdots, n$ :

$$
\Pi_{i}\left(S_{i}^{*} \mid S_{-i}^{*}\right) \geq \Pi_{i}\left(S_{i} \mid S_{-i}^{*}\right) \text { for every } S_{i} \neq S_{i}^{*}
$$

Our intention is to characterize the symmetric equilibrium of the model, but before proceeding with the analysis it is useful to note the following lemma:

Lemma 1 If $n<2 k$ there cannot be a zero-profit equilibrium and any equilibrium will involve firms making positive profit. If $n \geq 2 k$ there exists a zero-profit equilibrium in which each project attracts at least two bidding firms.

As long as the number of firms are sufficiently large, there will be a trivial zero profit Bertrand pricing equilibrium. But as the number of firms becomes smaller and $n<2 k$ in the constrained bidding environment any possible equilibrium will involve firms making positive profits as will be 
discussed below. In what follows we derive the symmetric equilibrium of the model which holds for the general case of any feasible value of $n$ and $k$. The equilibrium is completely mixed and is depicted in Figure 1. Formally,

Proposition 1 The symmetric equilibrium for the $n$ firms and $k$ projects environment is given by: $S_{1}^{*}=S_{2}^{*}=\cdots=S_{n}^{*}=\left\{q_{j n}^{*}, F_{j n}^{*}(b)\right\}_{j=1}^{k}$. Define the adjusted values, $v_{j n}$, as $v_{j n}=\sqrt[n-1]{V_{j}}$, and the harmonic mean of the adjusted values as $H_{k n}(v)=k /\left(\sum_{j=1}^{k} 1 / v_{j n}\right)$. Then the equilibrium probabilities of bidding on each project are given by: $q_{j n}^{*}=1-\frac{(k-1) H_{k n}(v)}{k v_{j n}}$, whereas $F_{j n}(b)$, the cumulative probability that the bidding price on project $j=1, . ., k$ is below $b$, is given by:

$$
F_{j n}^{*}(b)= \begin{cases}1 & \text { if } \quad b \geq V_{j} \\ \frac{v_{j}}{\sqrt[n-1]{b}} \frac{k \sqrt[n-1]{b}-(k-1) H_{k n}(v)}{k v_{j}-(k-1) H_{k n}(v)} & \text { if } Z_{n k} \leq b<V_{j} \\ 0 & \text { if } p<Z_{n k}\end{cases}
$$

where $Z_{n k}=\left(\frac{k-1}{k} H_{k n}(v)\right)^{n-1}$.

Finally, the above constitutes an equilibrium only if $Z_{n k}<V_{j}$ for $j=1, \cdots, k$.

Proof. All proofs are in the appendix.

\section{- - - Insert Figure 1 here - - -}

Note that even if there are a lot more bidding firms than projects $(n>>k)$, and though it is very likely that at least two firms will bid on each project, all firms achieve positive expected payoff in equilibrium. The intuition for this result stems from the fact that each bidding firm is constrained to bid only on a single project. In a mixed strategy equilibrium there is a positive probability that any firm will be the unique bidder on a project and will be able to win it at any bid value. ${ }^{6}$ This leads to positive expected equilibrium profits. In the spirit of the literature on constraints as a potential resolution to the Bertrand paradox (for example see Levitan and Shubik (1972) or Kreps and Scheinkman 1983) this paper highlights the role of restrictions placed on the bidders (in terms of the number of auctions they can bid on) in shifting the outcome away from a zero profit equilibrium.

The nature of the mixed strategy equilibrium guarantees equal expected profits for the firms regardless of the project they bid on. This is due to the fact that higher value projects attract more bidders (in expectation) creating more intense competition and resulting in equal profits across projects. Formally, consider the difference in the probabilities of a firm bidding on any two

\footnotetext{
${ }^{6}$ The probability that a firm will be the unique bidder on project $j$ is given by $\left(1-\frac{(k-1) H_{k n}(v)}{k v_{j n}}\right)$. $\left(1-\left(\frac{(k-1) H_{k n}(v)}{k v_{j n}}\right)^{n-1}\right)$
} 
projects $i$ and $j$ such that $V_{j}>V_{i}$ : We have that $q_{j}-q_{i}=\frac{H_{k n}(v)(k-1)}{k}\left(\frac{1}{v_{i n}}-\frac{1}{v_{j n}}\right)>0$. Firms have a higher probability of bidding on a larger value project. The number of incremental bids is enough to compete away the extra potential profits that the larger value project offers. But the interesting point is that the probability of bidding on each project approaches $\frac{1}{k}$ as the number of bidding firms become arbitrarily large $\left(\lim _{n \rightarrow \infty}\left(q_{j}\right)=\frac{1}{k}\right)$. Thus as the number of bidders increases all projects become more similar in terms of attracting any given bidder.

Let us now consider some comparative statics of the equilibrium profits. The expected profit each bidding firm makes is given by $Z_{n k}=\left(\frac{k-1}{k} H_{k n}(v)\right)^{n-1}$. Notice first that the harmonic mean is always smaller than the largest normalized project value and therefore it is less than the largest $v_{1 n}$. Thus, the per firm expected profit $\left(\frac{k-1}{k} H_{k n}(v)\right)^{n-1} \leq\left(\frac{k-1}{k} v_{1 n}\right)^{n-1}=V_{1 n}\left(\frac{k-1}{k}\right)^{n-1}$ as well as the total profit of all bidding firms $n\left(\frac{k-1}{k} H_{k n}(v)\right)^{n-1} \leq n V_{1 n}\left(\frac{k-1}{k}\right)^{n-1}$ are decreasing functions of $n$ (for large enough values of $n$ ) and approach zero in the limit. As the number of bidding firms increases the competition approaches the perfect Bertrand one.

Next note that increasing the value of any project clearly increases the expected profit of each firm. However it is interesting to investigate the impact of greater heterogeneity in the projects valuations on expected profits. One way of increasing heterogeneity while maintaining the average is to pick two projects, increase the value of the larger one while decreasing the value of the other by the same amount. The result will be a collection of projects with the same mean value but with a larger spread. We then find that increasing heterogeneity lowers the expected equilibrium profits of the firms. Formally, assume that project $i<j$ valuations were changed to $V_{i}+x$ and $V_{j}-x$ $x>0$. It is enough to show that the new harmonic mean of the normalized values is smaller. In other words, $\frac{k}{\sqrt[n-1]{V_{1}}+\ldots+\sqrt[n-1]{V_{k}}}>\frac{k}{\sqrt[n-1]{V_{1}}+\ldots+\sqrt[n-1]{V_{i}+x}+\sqrt[n-1]{V_{j}-x}+\sqrt[n-1]{V_{k}}}$ or $\sqrt[n-1]{V_{i}+x}+\sqrt[n-1]{V_{j}-x}>$ $\sqrt[n-1]{V_{i}}+\sqrt[n-1]{V_{j}}$ which is true because $\sqrt[n-1]{V_{i}+x}+\sqrt[n-1]{V_{j}-x}$ is an increasing function of $x$. This implies that for a fixed number of projects $k$, greater heterogeneity in the values of the projects as represented by a greater spread in project values leads to more intense competition among the bidders.

Finally, Proposition 1 also notes the existence condition $Z_{n k}<V_{j}$ for $j=1, \cdots, k$ which implies the condition that the lower bound of the bidding distribution should be below the valuation of the projects. This condition guarantees that the firms consider all the projects. Clearly for large $n$ the condition is satisfied but for sufficiently small project values or small number of firms the symmetric equilibrium in which firms consider all projects by totally mixing the project choice probabilities does not exist. 
It is interesting to consider what happens when the above existence condition is not satisfied. Conceivably, while firms might be constrained to bid on only one of the potential projects, they might choose in equilibrium to consider only a strict subset $S=\{1, \ldots, s\} s<k$ of the total number of projects. Such behavior can constitute a symmetric equilibrium in the subset of projects if firms consider only the higher value projects and their expected profits $Z_{n l}>V_{m}$ for all $l=m+1, . ., k$. Thus, if the difference in the project values is large enough there exist (symmetric) equilibria where all the firms are better off considering only some subset of the offered projects. As a numerical example consider the case of four projects with the following maximum willingness to pay by the buyers: $V_{1}=1600>V_{2}=800>V_{3}=500>V_{4}=200$. Firms can potentially consider only the two largest value projects, the three largest, or all four. The following table presents the per firm profit in the completely symmetric equilibrium as the number of participating firms increases.

\begin{tabular}{|c|c|c|c|}
\hline & \multicolumn{3}{|c|}{ Projects Considered } \\
\hline Number of Firms & Two Largest $(\mathrm{S}=2)$ & Three Largest $(\mathrm{S}=3)$ & All Four $(\mathrm{S}=4)$ \\
\hline $\mathrm{n}=2$ & $Z_{2,2}=533$ & $Z_{2,3}=516$ & $(*)$ \\
\hline $\mathrm{n}=3$ & $(*) Z_{3,2}=275$ & $Z_{3,3}=362$ & $(*)$ \\
\hline $\mathrm{n}=4$ & $(*) Z_{4,2}=139$ & $Z_{4,3}=246$ & $(*)$ \\
\hline $\mathrm{n}=5$ & $(*) Z_{5,2}=70$ & $(*) Z_{5,3}=165$ & $Z_{5,4}=176$ \\
\hline $\mathrm{n}=6$ & (*) $Z_{6,2}=35$ & $(*) Z_{6,3}=111$ & $Z_{6,4}=134$ \\
\hline
\end{tabular}

$\left(^{*}\right)$ - These profits do not constitute an equilibrium.

Note that when considering all four projects we need at least 5 participating firms to guarantee that the lower bound of the price distribution will be below the project value. When the number of firms participating is 3 or 4 the only symmetric equilibrium involves bidding on the three high value projects. While two firms might bid on the two or three highest value projects but can not get an equilibrium when bidding on all four. The overall point is that as the number of firms becomes large, each firm in equilibrium will bid on all projects with positive probability. But for small enough number of firms, it is possible that bidding on only a subset of firms can constitute an equilibrium. Furthermore, all firms can be better off considering only a subset of the available projects. Finally, we have the following corollary on the expected number of projects that receive a bid .

Corollary 1 The expected number of projects with at least one bidding firm is given by:

$$
E[\# \text { of projects }]=k-\left(Z_{n k}\right)^{\frac{n}{n-1}} \sum_{m=1}^{k} \frac{1}{v_{m n}^{n}}
$$




\section{Proof. See Appendix.}

Clearly, in equilibrium, some projects will not receive even a single bid but as the number of firms increases the number of projects that have at least one firm bidding for their completion increases and, in the limit approaches $k$ the total number of projects.

It is interesting to note that the model presented in this section is analytically analogous to a competition between Internet Shopping Agents (ISA), where consumers use ISAs to compare prices (See Iyer and Pazgal 2003). Specifically, consider $n$ firms offering a homogeneous good for sale, consumers need at most one unit of a desired homogeneous good and will buy from the cheapest retailer they can find as long as the price is below their reservation price of $R$. All consumers search for the cheapest store using one and only one ISA. Assume that there are $k$ competing ISAs, each is frequented by $T_{j} j=1, \ldots, k$ consumers. The similarity to the bidding process described earlier comes from the fact that each firm can only register with a single ISA. The firms must simultaneously decide which ISA they want to participate in and what prices they charge for the good. Clearly, the above analysis can be applied to characterize a mixed strategy equilibrium both on the part of pricing strategies and ISA participation.

\subsection{Bidding on Multiple Projects $(m>1)$}

In the previous section we analyzed the case in which the firms were constrained to bid on only one project. We now generalize the model to the case of general bidding restriction in which the firms may bid on any $1 \leq m<k$ projects. In other words, as $m$ becomes larger firms face less severe restrictions and can bid on more of the potential projects. Let firms bid on $m<k$ projects in expectation. Let $q_{j}$ be the probability that a firm will bid on project $j$. Then in this case a feasible strategy for a firm requires that $\sum_{j=1}^{k} q_{j}=m<k$ and $q_{j} \leq 1$. The following proposition characterizes the equilibrium.

Proposition 2 The symmetric equilibrium for the $n$ firms and $k$ projects environment where firms bid on only $m<k$ projects (in expectation) is given by: $S_{1}^{*}=S_{2}^{*}=\cdots=S_{n}^{*}=\left\{q_{j n}^{*}, F_{j n}^{*}(b)\right\}_{j=1}^{k}$. Define the adjusted values, $v_{j n}$, as $v_{j n}=\sqrt[n-1]{V_{j}}$, and the harmonic mean of the adjusted values as $H_{k n}(v)=k / \sum_{j=1}^{k} \frac{1}{v_{j n}}$. Then the equilibrium probabilities of bidding on each project are given by: $q_{j n}^{*}=1-\frac{(k-m) H_{k n}(v)}{k v_{j n}}$, while $F_{j n}(b)$, the cumulative probability that the bidding price on project $j=1, . ., k$ is below $b$, is given by:

$$
F_{j n}^{*}(b)= \begin{cases}1 & \text { if } \quad b \geq V_{j} \\ \frac{v_{j}}{\sqrt[n-1]{b}} \frac{k \sqrt[n-1]{b}-(k-m) H_{k n}(v)}{k v_{j}-(k-m) H_{k n}(v)} & \text { if } Z_{n k} \leq b<V_{j} \\ 0 & \text { if } p<Z_{n k}\end{cases}
$$


where $Z_{n k}=\left(\frac{k-m}{k} H_{k n}(v)\right)^{n-1}$.

Finally, the above constitutes an equilibrium only if $Z_{n k}<V_{j}$ for $j=1, \cdots, k$.

Proof. See Appendix.

We can note that the equilibrium profits are $Z_{n k}=\left(z_{n k}\right)^{n-1}=\left(\frac{k-m}{k} H_{k n}(v)\right)^{n-1}$. Even if $m$ is infinitesimally smaller than $k$, the profits are bounded away from zero. Hence even a weak restriction on the participation of the firms helps in resolving the Bertrand paradox. Furthermore, profits are decreasing in $m$ i.e., the equilibrium profits decrease as firms are able to bid on more and more projects. ${ }^{7}$

\subsection{Bidder Heterogeneity}

In this section, we extend the analysis to consider heterogeneity among bidders in terms of the number of projects they are constrained to bid on. This can represent the differences in resources and capacity among the bidding firms. Let $n_{1}$ be the number of type 1 firms that are able to bid on $m_{1}$ projects while the remaining $n_{2}=\left(n-n_{1}\right)$ be the number of type 2 firms that are able to bid on $m_{2}$ projects, where $m_{1}>m_{2}$. Thus the type 1 firms are less constrained and are able to bid on more projects. We derive the symmetric equilibrium where all firms of a given type behave in the same way. Define $q_{j}$ as the probability that type 1 firm bids on project $j$ and let $W_{j}(b)$ be the probability that it bids above $b$ on project $j$. Let $s_{j}$ and $U_{j}(b)$ be their counterparts for the bidding behavior of type 2 firms.

The profit functions for the two types of firms are as shown below: For a type 1 firm we get (suppressing the subscript $n$ ),

$$
\Pi_{j}(b)=b\left(q_{j} W_{j}(b)+\left(1-q_{j}\right)\right)^{n_{1}-1}\left(s_{j} U_{j}(b)+\left(1-s_{j}\right)\right)^{n_{2}}
$$

and similarly for a type 2 firm we get,

$$
\Pi_{j}(b)=b\left(q_{j} W_{j}(b)+\left(1-q_{j}\right)\right)^{n_{1}}\left(s_{j} U_{j}(b)+\left(1-s_{j}\right)\right)^{n_{2}-1}
$$

Given the above profit functions we characterize the equilibrium in the following proposition:

\footnotetext{
${ }^{7}$ This result also holds when each bidder can choose a subset of size $m$ projects (out of all possible subsets of size $m$ ) and bids on all the projects in the subset with probability one. Assume that the firm's bidding on each project depends upon the project's value and not on the identity of the subset chosen. The equilibrium of this case is similar to the one in Proposition 2, except that a firm has more freedom in choosing the equilibrium probabilities assigned to the choice of each subset.
} 
Proposition 3 With bidder heterogeneity, in a symmetric equilibrium where all firms of a given type behave identically, we have that,

- The equilibrium probabilities of the type 1 and type 2 firms of bidding on project $j$ are respectively $q_{j}=1-\frac{\left(k-m_{1}\right) H_{k n}(v)}{k v_{j n}}$ and $s_{j}=1-\frac{\left(k-m_{2}\right) H_{k n}(v)}{k v_{j n}}$.

- The equilibrium profits the type 1 and type 2 firms are respectively

$$
\begin{aligned}
& Z_{1}=\left(k-m_{2}\right)^{n_{2}}\left(k-m_{1}\right)^{n_{1}-1}\left(\frac{H_{k n}(v)}{k}\right)^{n-1} \text { and } \\
& Z_{2}=\left(k-m_{2}\right)^{n_{2}-1}\left(k-m_{1}\right)^{n_{1}}\left(\frac{H_{k n}(v)}{k}\right)^{n-1}
\end{aligned}
$$

- The c.d.f of the bidding distributions are as follows:

$$
\begin{aligned}
& F_{j}^{\text {type } * 1}(b)= \begin{cases}1 & \text { if } \quad b \geq V_{j} \\
\frac{v_{j}}{n-1 / \sqrt{b}} \frac{k(\sqrt[n-1]{b})-\left(k-m_{1}\right) H_{k n}(v)}{k v_{j}-\left(k-m_{1}\right) H_{k n}(v)} & \text { if } L_{2}=\left(\left(k-m_{2}\right) \frac{H_{k n}(v)}{k}\right)^{n-1} \\
\frac{\rho v_{j}}{n_{1}-\sqrt[1]{b}} \frac{k(\sqrt[n]{1}-1 / \sqrt{b})-\left(k-m_{1}\right) H_{k n}(v)}{k v_{j}-\left(k-m_{1}\right) H_{k n}(v)} & \text { if } Z_{1} \leq b<L_{2}=\left(\left(k-m_{2}\right) \frac{H_{k}}{k}\right. \\
0 & \text { if } \quad b<Z_{1}=\left(k-m_{2}\right)^{n_{2}}\left(k-m_{1}\right)^{n}\end{cases} \\
& \text { where } \rho=\left(\left(k-m_{2}\right)\left(\frac{H_{k n}(v)}{k}\right)\right)^{\frac{n_{2}}{n_{1}-1}} \\
& F_{j}^{\text {type } * 2}(b)=\left\{\begin{array}{lll}
1 & \text { if } \quad b \geq V_{j} \\
\frac{v_{j}}{n-\sqrt[1]{b}} \frac{k \sqrt[n-1]{b}-\left(k-m_{2}\right) H_{k n}(v)}{k v_{j}-\left(k-m_{2}\right) H_{k n}(v)} & \text { if } \quad L_{2} \leq b<V_{j} \\
0 & \text { if } \quad b<L_{2}=\left(\left(k-m_{2}\right) \frac{H_{k n}(v)}{k}\right)^{n-1}
\end{array}\right.
\end{aligned}
$$

Proof. See Appendix.

Heterogeneity among the bidders (in terms of the number of projects they can bid on) creates some interesting effects. Since $m_{1}>m_{2}$, we have $Z_{1}>Z_{2}$. This gives us the first result that the type 1 firms that can bid on more projects get higher expected equilibrium profits. This is true regardless of the number of type 1 firms. To understand this, notice that the lower bound of the support of the type 1 firms' bid distribution is lower than $L_{2}=\left(\left(k-m_{2}\right) \frac{H_{n}}{k}\right)^{n-1}$ which is the lower bound of the type 2 firms. The firms that are less constrained are likely to bid more aggressively for all projects. This means that when bidding below $L_{2}$ the type 1 firms face competition only from the other type 1 firms. Because of this they enjoy a higher equilibrium probability of being the only bidding firm on a project which results in their making higher profits.

Another question is how the individual firm and the total industry profits change with bidder heterogeneity. Suppose all bidders were homogenous to begin with and there are $n$ firms each 
bidding on $m$ projects. The total industry profit will be $n\left((k-m) \frac{H_{k n}(v)}{k}\right)^{n-1}$. Now suppose that $n_{1}$ firms can bid on $m_{1}>m$ projects. Each firm's profits would be $(k-m)^{n_{2}}\left(k-m_{1}\right)^{n_{1}-1}\left(\frac{H_{k n}(v)}{k}\right)^{n-1}$ which is higher than the firm profits in the homogenous case. While the other $\left(n_{2}=n-n_{1}\right)$ firms will each make $(k-m)^{n_{2}-1}\left(k-m_{1}\right)^{n_{1}}\left(\frac{H_{k n}(v)}{k}\right)^{n-1}$ which is lower than the firm profits in the homogenous case. So the new total industry profit is

$$
(k-m)^{n_{2}-1}\left(k-m_{1}\right)^{n_{1}-1}\left(\frac{H_{k n}(v)}{k}\right)^{n-1}\left(n_{1}(k-m)+n_{2}\left(k-m_{1}\right)\right) .
$$

By comparing the above expression with the total industry profits for the homogenous case it can be easily shown that the total profits decrease with bidder heterogeneity.

\section{Extensions}

In this section, we provide two extensions to the basic model. First we take up the role of bidder commitment to projects and investigate how it will affect the equilibrium. Thereafter we analyze the effect of uncertainty about project valuations on the bidder strategies and the equilibrium. For both these extensions we present the results using the simpler case of two potential projects and $n$ bidders, though the results also generalize to the case of $k$ projects.

\subsection{Commitment to Projects}

As was previously shown a positive profit equilibrium in this model can not have more than one firm committing to bidding on a single project with probability one. In this section, we ask what would be the outcome if there is a single firm committed to each project and is guaranteed to bid on their assigned project. Indeed, this question has a relevance in the actual examples that we presented in the introduction of the paper. In the road construction bidding environment, there are local construction firms in many of the counties in Georgia which always bid on the projects that are offered within the county. We analyze the role of this commitment of a firm to always bid on a project by using the case of a two project environment.

Proposition 4 In a two project environment, when firm $i$ is committed to bid on project $i$ for $i=$ 1,2 , the symmetric equilibrium for the remaining $(n-2)$ firms is given by: $S_{3}^{*}=S_{4}^{*}=\cdots=S_{n}^{*}=$ $\left(\left(r_{1 n}=\frac{w_{1 n}}{w_{1 n}+w_{2 n}}, G_{1 n}(b)\right),\left(r_{2 n}=\frac{w_{2 n}}{w_{1 n}+w_{2 n}}, G_{2 n}(b)\right)\right)$, where the adjusted values $w_{j n}=\sqrt[n-2]{V_{j}}$, and $G_{j n}(b)$, the cumulative probability that the bidding price on project $j=1,2$ is below $b$, is given by: 


$$
G_{j n}(b)=\left\{\begin{array}{lll}
1 & \text { if } \quad b \geq V_{j} \\
\frac{w_{1 n}+w_{2 n}}{w_{j n}}-\frac{w_{(3-j) n}}{n-2} \sqrt{b} & \text { if } \quad Y_{n} \leq b<V_{j} \\
0 & \text { if } \quad p<Y_{n}
\end{array}\right.
$$

where $Y_{n}=\left(\frac{w_{1 n} w_{2 n}}{w_{1 n}+w_{2 n}}\right)^{n-1}$.

Furthermore,

$$
\begin{aligned}
& S_{1}^{*}=\left(\left(\alpha_{1}=r_{1 n}=\frac{w_{1 n}}{w_{1 n}+w_{2 n}}, G_{1 n}(b)\right),\left(q_{2 n}=0, \cdot\right)\right) \\
& S_{2}^{*}=\left(\left(q_{1 n}=0, \cdot\right),\left(\alpha_{2}=r_{2 n}=\frac{w_{2 n}}{w_{1 n}+w_{2 n}}, G_{2 n}(b)\right)\right)
\end{aligned}
$$

Proof. See Appendix.

Figure 2 presents a schematic of the equilibrium strategy.

\section{- - - Insert Figure 2 here - - -}

It is interesting to note that the above equilibrium is identical to the original symmetric equilibrium with one less participating firm. Hence all the properties that we proved before still hold for this equilibrium. Furthermore, because the equilibrium behavior is as if there is one less participating firm, this equilibrium implies greater expected profit for all the bidders.

\subsection{Uncertainty in Project Valuations}

We now consider bidder uncertainty about the project valuations. Looking back at the road construction example, the bidders are likely to be more certain about the maximum willingness to pay of the local government for routine projects like annual road maintenance and repairs than for the construction of new roads. In any given time the projects available for bidding are likely to consist of a mix of projects which vary in how uncertain their valuations are for the bidders.

Consider the example of $n$ firms bidding on two projects $(k=2)$. Bidders are certain about the valuation of one of the projects which has a (maximum) value $V_{1}$. Bidders have uncertain valuations for project 2 and assume it can have a value of $H$ with probability $\beta$ and $L$ with probability $(1-\beta)$ with the interpretation that the bidders are not sure about the maximum value or willingness to pay of the party needing the project. On the other hand, the party offering the project for bidding knows its own maximum willingness to pay. Thus if a bidder bids above $L$ and it turns out that the value of the project was only $L$ she gets zero payoff even if her bid was the lowest one submitted.

The solution strategy proceeds by noting that by bidding up to $L$ a bidder can guarantee winning the uncertain project (project 2) when she is the lowest bidder. But by bidding even an 
infinitesimal amount above $L$ she has a probability $(1-\beta)$ of getting zero payoff despite being the lowest bidder on the project. Therefore, if $L>\beta H$ the bidders will treat the high value project as if its value is $L$. On the other hand when the potential of high payoffs are very large high bidders would consider it as having a known value of $\beta H$ and will only bid above $L$. Only in the intermediate case will the bidding distribution require a new characterization. The following proposition presents the equilibrium formally.

Proposition 5 Consider $n$ firms bidding on two projects, the first with known value of up to $V_{1}$ and the second having uncertain value of either $H$ with probability $\beta$ or $L$ with probability $(1-\beta)$. Then when $\beta H \geq L$ the equilibrium bidding is:

- When $Z>L$ the bidders behave as if they are facing two projects with values $V_{1}$ and $\beta H$.

- When $Z<L$ the probability of each firm bidding on project 1 is given by $q_{1}=\frac{v_{1}}{v_{1}+\gamma h}$. The cumulative probability that the bidding price on project 1 is above b, is given by $W_{1 n}(b)$ :

$$
W_{1 n}(b)=\gamma h\left(\frac{1}{\sqrt[n-1]{b}}-\frac{1}{v_{1}}\right) \quad \text { for } Z \leq b \leq V_{1}
$$

and the equilibrium bidding on the uncertain project is

$$
W_{2 n}(b)=\left\{\begin{array}{lll}
\frac{v_{1}}{\gamma h}\left(\frac{h}{\sqrt[n-1]{b}}-1\right) & \text { if } & L / \beta \leq b \leq H \\
v_{1}\left(\frac{1}{\sqrt[n-1]{b}}-\frac{1}{\gamma h}\right) & \text { if } & Z \leq b \leq L
\end{array}\right.
$$

where $v_{1}=\sqrt[n-1]{V_{1}}, h=\sqrt[n-1]{H}$ and $\gamma=\sqrt[n-1]{\beta}$ as well as $Z=\left(\frac{\gamma h v_{1}}{v_{1}+\gamma h}\right)^{n-1}$.

Proof. See Appendix.

Note that the expected valuation of the uncertain project $\mu=\beta H+(1-\beta) L$ does not play a role in the equilibrium. Conditional on being the lowest bidder, a bidder will win the project for sure if the bid if below $L$, but will win it only with probability $\beta$ if the bid is above $L$. If the higher valuation or the probability of its occurring is not too high $(\beta H<L)$ then all the bidding firms will not find it attractive enough to bid high to extract surplus in the event that the valuation was indeed high. Thus the equilibrium is as if the bidders face two projects of valuations $V_{1}$ and $V_{2}=L$.

Consider now the case in which the probability of the high state and the valuation in the high state is sufficiently high $(\beta H \geq L)$. Now the firms will find it attractive to bid in manner so as to extract surplus in the event that the valuation was indeed high even though this would mean 
getting zero payoff if the valuation turned out to be $L$. In such a case there are two possibilities. If the valuation of the low state $L$ is sufficiently low $(Z>L)$, then the firms will essentially ignore this state and the bidding will be such that the project will not be awarded if the valuation indeed turned out to be low. Thus the bidding firms behave as if they are facing two certain projects of valuations $V_{1}$ and $\beta H$. On the other hand, if $Z<L$ then the equilibrium is one in which the bidding firms consider winning the projects even in the event that the valuation was low $^{8}$.

In the more general case when both projects' valuations are uncertain the same intuition and results still hold. Assume that both projects have independent valuations that can be either $H$ with probability $\beta$ or $L$ with probability $(1-\beta)$. If $\beta H<L$ the bidders will treat both projects as if their valuation is $L$ for an expected payoff of $Z_{n}(L, L)=\left(\frac{1}{2}\right)^{n-1} L$. If, on the other hand, $\beta H>L$ the expected payoff for the bidders is $Z_{n}(\beta H, \beta H)=\left(\frac{1}{2}\right)^{n-1} \beta H$. The exact bidding distribution in this case depends on the relative magnitude of $Z_{n}(\beta H, \beta H)$ and $L$. As long as $\left(\frac{1}{2}\right)^{n-1} \beta H>L$ the distribution is identical to the one we found for two projects of equal value $\beta H$. But for larger $n$ when we have $\left(\frac{1}{2}\right)^{n-1} \beta H<L$ the equilibrium distribution is comprised of a union of two intervals as in proposition 5 .

We now turn to investigate the impact of increased uncertainty about the valuation of the second project on the expected revenue of the bidding firms.

Proposition 6 Consider $n$ firms bidding on two projects, the first with known value of up to $V_{1}$ and the second having uncertain value of either $H$ with probability $\beta$ or $L$ with probability $(1-\beta)$. Increasing the uncertainty about the second project valuation while preserving its expected valuation $\mu$ leads to (weakly) lower expected profits for the bidders.

Proof. See Appendix.

Thus increasing uncertainty of the second project while preserving its expected valuation implies greater bidder competition.

\section{$4 \quad$ Empirical Findings}

We designed and conducted computer controlled lab experiment involving real monetary incentives which tested the predictions of the model. Participants were enrolled into the study and were given the following cover and task description:

\footnotetext{
${ }^{8}$ Note, however, that the expected revenue for the bidders depend only on whether $\beta H$ is smaller or larger than $L$. Specifically, the expected profit in the symmetric equilibrium with $n$ firms is given by $\left(\frac{v_{1} v_{2}}{v_{1}+v_{2}}\right)^{n-1}$ where $v_{1}=\sqrt[n-1]{V_{1}}$ and $v_{2}=\sqrt[n-1]{\max (\beta H, L)}$.
} 
You are a sales representative for the company "Phonewidget Inc." You need to submit a sealed bid for installing a new phone system for two important and well-known clients $\mathrm{A}$ and $\mathrm{B}$. The clients will award the project to the company with the lowest bid. Assume that while you are deciding your bidding strategy you do not face any costs of bidding and therefore your payoff is completely determined by the price that you bid. Because the clients are well known, you know their willingness to pay for the respective projects (i.e., you know the maximum amount of money they are willing to spend on the project.) Client $\mathrm{A}$ is willing to pay no more than $\$ V_{A}=$ for the completion of its project while client $\mathrm{B}$ is willing to pay no more than $\$ V_{B}=$ for the completions of its project. Because the projects are large your company can at best complete only one of the two projects. You cannot bid on both projects because the penalty to your company of not completing a project after winning it is extremely high (these include non completion penalties and also the loss of reputation of your company). You can therefore only submit a bid for ONE project. Please submit your bid in whole dollars. There are $n=$ other sales representatives of other competitor firms besides your own (so there are $n+1$ competitors in total including yourself) that are participating in the bidding. The other firms face a situation similar to that of your firm: they too have no costs and each can bid only on ONE project as well. All firms must submit their bid simultaneously and in writing and you will not know which project each of your competitors are bidding on and how much they are bidding. Please decide which project you will bid on and the dollar value of the bid and input your answers into the computer program. Once all your competitors submit their bids you will be informed if you won or not.

At the end of the session we also asked the following question: Can you explain your bidding strategy and the reasoning behind it?

The above scenario was repeated 5 times for each of the subjects varying the values of $\$ V_{A}, \$ V_{B}$, and $n$. For each bidding exercise the subjects were randomly matched in groups of $n$, subjects won an amount equal to their bids only when they offered the lowest bid on their chosen project. At the end of the experiment subjects received $\$ 5$ (for participation) plus their total winnings (scaled down by a factor of 1000 .) The projects' values were taken from $\$ 1000, \$ 3000, \$ 5000, \$ 8000, \$ 10,000$ with $\$ V_{A}<\$ V_{B}$ thus we had 10 different possible pairs of values each equally likely. The total number of bidders was 2 (35\% of the situations), $3(25 \%), 5(25 \%)$ or $8(15 \%)$ where the number in parentheses represents the frequency.

Thus our experimental design is a $10 \times 4$ one. The subjects were 248 students from a Midwestern university (65\% of them were male) and ended with 1238 observations divided between the 40 
different conditions. The highest payout was $\$ 20.35$ and the lowest was $\$ 5.00$ and the average was $\$ 10.15$. Figure 3 presents an example of the cumulative bidding distribution achieved by bidders on the high value project when they were faced with two projects of values $V_{1}=3000$ and $V_{2}=1000$ and one other competing firm.

\section{- - - Insert Figure 3 Here - . -}

We first analyzed the probability of bidding on the high value project as a function of the project valuations $V_{A}$ and $V_{B}$ and the number of bidding firms. We ran a binary logit on the probability of choosing the high value project. The results are summarized in Table 1 below. Clearly all coefficients besides the constant are significant at the 0.001 level and have the expected sign. For each additional bidding firm the odds of bidding on the high value project decrease by $12.4 \%\left(1-e^{-0.133}\right)$. Increasing the value of the high value project by $\$ 100$ increases the odds of bidding on it by $1.9 \%$ while increasing the value of the low value project (holding all else fixed) by $\$ 100$ decreases the odds of bidding on the high value project by $2.2 \%{ }^{9}$ Finally, from the verbal answers to our question about the reasons for the bidding strategy it is clear that participants in the experiment tried to maximize their earnings. Most participants responded by saying that they bid on a project that "...gave the best chances of winning the auction while not lowering the bid too much." However, participants did not directly articulate how they determined the exact dollar value of their bid.

\begin{tabular}{|l|ll|ll|}
\hline & \multicolumn{2}{|l|}{ Regression 1 } & \multicolumn{2}{l|}{ Regression 2 } \\
\hline constant & 0.837 & $(0.28)$ & 0.523 & $(0.30)$ \\
\hline$V_{\text {High }}$ (in hundreds) & 0.022 & $(0.004)$ & 0.022 & $(0.004)$ \\
\hline$V_{\text {Low }}$ (in hundreds) & -0.020 & $(0.004)$ & -0.020 & $(0.004)$ \\
\hline Number of firms & -0.133 & $(0.04)$ & -0.130 & $(0.03)$ \\
\hline Gender (1=female) & & & 0.496 & $(0.160)$ \\
\hline Log Likelihood & -499 & -494 & \\
\hline
\end{tabular}

Table 1: Binary logit coefficients and their standard errors

We now turn to investigate the value of the bid conditional on the chosen project. As expected, the average bid on the high value project was higher than the average bid on the lower value project in 38 of the 40 cases. (A t-test for the differences in matched means showed a significant difference at the $p=0.001$ level.) On the other hand, the lowest bid offered was on the high value project 24

\footnotetext{
${ }^{9}$ Interestingly the gender of the bidder had an impact on the probability of bidding on the high value project. Fixing the valuation of the projects and the number of bidders the odds of women bidding on the high value project are $64 \%$ higher than men.
} 
out of the 40 cases. Specifically, the $95 \%$ confidence interval for the ratio of the lowest bid on the high value project to the lowest bid on the low value project is $[0.82,1.34]$ which is in accordance with our theory that predicts equal lower bounds.

We also ran a regression to measure the change in the average (and median) bids as we varied the number of bidding firms and project valuations. The results for the high and low value projects are presented below

$$
\begin{array}{r}
E_{h}=799+0.425 V_{h i g h}-119 n \\
(379) \quad(0.04) \quad(43) \\
E_{l}=591+0.693 V_{\text {low }}-128 n
\end{array}
$$

$E_{h}$ and $E_{l}$ are the expected bids on the high and low value projects respectively, $n$ is the total number of bidding firms. The numbers in parenthesis are the standard errors of the coefficients so the project valuations and number of bidding firms are significant at the $p=0.001$ level. From the regression we can see that as the total number of bidders increase the average bid decreases whereas the bids are increasing with the seller's willingness to pay for the project. Both of these results are predicted by the theory. The somewhat surprising finding is that in neither case the value of the other project had any significant impact on the value of the bid. Repeating the regressions for the median bids rather than the average yielded the exact same results.

\section{Conclusion}

In this paper we examine the competitive bidding of firms that face simultaneous potential projects and operate under restrictions on their bidding strategy. It was Edgeworth (1925) who highlighted the role of capacity constraints in resolving the Bertrand paradox. Over the years several resolutions to the paradox, have been provided in the literature (See Levitan and Shubik (1972), Kreps and Scheinkman (1983) or Baye and Morgan 2002). In a simultaneous auction environment this paper highlights the role of participation constraints in generating outcomes that allow firms to price above marginal costs. When firms each can bid on exactly one of several simultaneously offered projects, an equilibrium exists in which each bidder can have a positive equilibrium expected profit even if the projects are all identical. In fact, as long as the number of bidders is not too large compared to the number of projects there cannot exist a zero-profit equilibrium for the bidding firms. Despite 
the fact that the bidders are homogenous and the expected number of firms actually bidding on each project is positive, prices remain above marginal cost because of the possibility that each firm in equilibrium might be the only firm bidding on the project. As expected the probability of bidding and the expected bid on a high value project is higher than that on a lower value project, and depends of the ratio of the values. Interestingly the bidding on any project becomes equiprobable (despite different valuations) as the number of bidding firms become arbitrarily large. Thus as the number of bidders increases all projects becomes similar in terms of attracting any given bidder.

In the general case in which the restrictions on bidding are relaxed and where each bidding firm can bid on more than one project, we find that as firms are able to bid on more of the available projects the intensity of competition between the bidders increases and the equilibrium profits decrease. In contrast bidder commitment to bid on specific projects increases the profits of all firms. We also examine the effect of heterogeneity among bidders in terms of the number of projects that they are constrained to bid on. Firms that have less of a constraint and which can bid on more projects achieve greater equilibrium profits regardless of the mix of the firms in the industry. Finally, we analyze the effect of uncertainty in project valuations for bidders and show greater uncertainty in project valuations decreases the equilibrium profits. 


\section{References}

[1] Baye M. J. and J. Morgan (2002) "Winner-take-all Price Competition," Economic Theory 19 pp.271-282.

[2] Benoit J. P. and Krishna V. (2001) "Multiple Object Auctions with budget constrained Bidders," Review of Economic Studies vol 68. pp 155-179

[3] Che Y. K. and I. Gale (1998) "Standard Auctions with Financially Constrained Bidders," Review of Economic Studies, vol 65 , 1-21;

[4] Dasgupta, P., Maskin, E. (1986) "The existence of equilibrium in discontinuous economic games, I: Theory," Review of Economic Studies LIII, 1-26.

[5] Edgeworth, F, (1925) "The Pure Theory of Monopoly," In: Edgeworth, F. (Ed.), Papers Relating to Political Economy, Vol. 1. Burt Franklin, New York.

[6] Engelbrecht-Wiggans R. and R. J. Webber (1979) "An Example of a Multi-Object Auction Game," Management Science vol. 25 pp. 1272-1277

[7] Harrington, J., (1989) "A re-evaluation of perfect competition as the solution to the Bertrand price game," Mathematical Social Sciences 17 pp.315-328.

[8] Iyer, G. and A. Pazgal (2003) "Internet Shopping Agents: Virtual Colocation and Competition," Marketing Science, vol. 22, 1, pp. 85-106.

[9] Kreps D. M. and J. Scheinkman (1983) "Quantity Precommitment and Bertrand Competition yields Cournot outcomes," Bell Journal of Economics, 14, 326-337

[10] Levitan R. and M. Shubik (1972) "Price Duopoly and Capacity Constraints," International Economic Review, Vol. 13, No. 1, pp. 111-122.

[11] Palfrey T. R. (1980) "Multiple Object, Discriminatory Auctions With bidding Constraints: A Game Theoretic Analysis," Management Science, Vol. 26, pp. 935-946. 


\section{Appendix}

Proof of Proposition 1. Let $q_{j n}=q_{j}$ be the probability that a firm will bid on project $j$, we require $\sum_{j=1}^{k} q_{j}=1$. Let $W_{j n}(b)=1-F_{j n}(b)$ be the symmetric probability ${ }^{1}$ of a firm bidding higher than $b$ on project $j=1, \ldots, k$. The profit of each firm when bidding $b$ on project $j$ is given by

$$
\Pi_{j}(b)=b\left(q_{j} W_{j n}(b)+\left(1-q_{j}\right)\right)^{n-1}
$$

In other words, the firm would win the project if all the other firms either bid above $b$, or bid on other projects. A firm will utilize a mixed strategy in equilibrium only if it is completely indifferent between all possible potential bids and across all projects. Hence we require $\Pi_{1}(b)=$ $\cdots=\Pi_{k}(b)=$ Const for every $b$ in the support of the equilibrium. Using the boundary conditions $\Pi_{1}\left(b \rightarrow V_{1}\right)=\cdots=\Pi_{k}\left(b \rightarrow V_{k}\right)=$ Const gives the following conditions for every $j$

$$
V_{j}\left(1-q_{j}\right)^{n-1}=\text { Const }=Z_{n k}
$$

The above condition can be written as $v_{j n}\left(1-q_{j}\right)=z_{n k}$, where $v_{j n}=\sqrt[n-1]{V_{j}}$ and $z_{n k}=\sqrt[n-1]{Z_{n k}}$. Summing the above equations over all the projects yields $k-\sum_{j=1}^{k} q_{j}=z_{n k} \sum_{j=1}^{k} \frac{1}{v_{j n}}$ or,

$$
z_{n k}=\frac{k-1}{\sum_{j=1}^{k} \frac{1}{v_{j n}}}=\frac{k-1}{k} H_{k n}(v)
$$

The next step is to calculate $q_{j}: v_{j n}\left(1-q_{j}\right)=\frac{k-1}{k} H_{k n}(v)$, or $q_{j}=1-\frac{(k-1) H_{k n}(v)}{k v_{j n}}$. Clearly the lower bound of the bidding distribution is $Z_{n k}$, and will be the same for all projects. Explicitly it is given by $Z_{n k}=\left(z_{n k}\right)^{n-1}=\left(\frac{k-1}{k} H_{k n}(v)\right)^{n-1}$. Finally we can solve for the bid distribution function. For project $j$ we have,

$$
b\left(q_{j} W_{j n}(b)+\left(1-q_{j}\right)\right)^{n-1}=\left(z_{n k}\right)^{n-1}
$$

And after taking the $(n-1)$ root and rearranging:

$$
W_{j n}(b)=\frac{(k-1) H_{k n}(v)}{(k-1) H_{k n}(v)-k v_{j n}} \frac{v_{j n}-\sqrt[n-1]{b}}{\sqrt[n-1]{b}}
$$

Finally translating this back to the $c d f$ we get the desired results.

Proof of Corollary 1. Let $I_{j}$ be the indicator function of project $j$. It takes the value 1 if at least one firm bids on the project and zero otherwise. Clearly, $\operatorname{Pr}\left[I_{j}=1\right]=1-\left(1-q_{j}\right)^{n}$ and the

\footnotetext{
${ }^{1}$ It is straightforward to show using techniques similar to that in Dasgupta and Maskin (1986) that the symmetric equilibrium is comprised of bidding functions on each project that must be completely mixed, atomless and connected.
} 
expectation is:

$$
\begin{aligned}
E[\# \text { of projects }] & =E\left[\sum_{m=1}^{k} I_{m}\right]=k-\sum_{m=1}^{k}\left(1-q_{j}\right)^{n}=k-\sum_{m=1}^{k}\left(\frac{k-1}{k} \frac{H_{k n}(v)}{v_{m n}}\right)^{n} \\
& =k-\left(\frac{k-1}{k} H_{k n}(v)\right)^{n} \sum_{m=1}^{k}\left(\frac{1}{v_{m n}}\right)^{n}=k-\left(Z_{n k}\right)^{\frac{n}{n-1}} \sum_{m=1}^{k} \frac{1}{v_{m n}^{n}}
\end{aligned}
$$

Proof of Proposition 2. Let $q_{j n}=q_{j}$ be the probability that a firm will bid on project $j$, we require $\sum_{j=1}^{k} q_{j}=m<k$ (and must check that $q_{j} \leq 1$ ).

Let $W_{j n}(b)=1-F_{j n}(b)$ be the symmetric probability of a firm bidding higher than $b$ on project $j=1, \ldots, k$. The profit of each firm when bidding $b$ on project $j$ is given by

$$
\Pi_{j}(b)=b\left(q_{j} W_{j n}(b)+\left(1-q_{j}\right)\right)^{n-1}
$$

In a mixed strategy equilibrium the firm should be indifferent between all possible potential bids. In other words, $\Pi_{1}(b)=\cdots=\Pi_{k}(b)=$ Const for every $b$ in the support of the equilibrium. Using the boundary conditions $\Pi_{1}\left(b \rightarrow V_{1}\right)=\cdots=\Pi_{k}\left(b \rightarrow V_{k}\right)=$ Const gives the following conditions for every $j$

$$
V_{j}\left(1-q_{j}\right)^{n-1}=\text { Const }=Z_{n k}
$$

The above condition can be written as $v_{j n}\left(1-q_{j}\right)=z_{n k}$, where $v_{j n}=\sqrt[n-1]{V_{j}}$ and $z_{n k}=$ $\sqrt[n-1]{Z_{n k}}$. Summing the above equation over all the projects yields $k-\sum_{j=1}^{k} q_{j}=z_{n k} \sum_{j=1}^{k} \frac{1}{v_{j n}}$ or, $z_{n k}=\frac{k-m}{\sum_{j=1}^{k} \frac{1}{v_{j n}}}=\frac{k-m}{k} H_{k n}(v)$.

The next step is to calculate $q_{j}: v_{j n}\left(1-q_{j}\right)=\frac{k-m}{k} H_{k n}(v)$, or $q_{j}=1-\frac{(k-m) H_{k n}(v)}{k v_{j n}}$. We need to make sure that $\frac{(k-m) H_{k n}(v)}{k v_{j n}}<1$ for every $v_{j}$ but this is equivalent to $\mathrm{Z}_{n k}<V_{j}$.

Clearly the lower bound of the bidding distribution is $Z_{n k}$, and is the same for all projects. Explicitly it is given by $Z_{n k}=\left(z_{n k}\right)^{n-1}=\left(\frac{k-m}{k} H_{k n}(v)\right)^{n-1}$. Finally we can solve for the bid distribution function. For project $j$ we have

$$
\begin{gathered}
b\left(q_{j} W_{j n}(b)+\left(1-q_{j}\right)\right)^{n-1}=\left(z_{n k}\right)^{n-1} \\
b\left(\left(1-\frac{(k-m) H_{k n}(v)}{k v_{j}}\right) w+\frac{(k-m) H_{k n}(v)}{k v_{j}}\right)=\frac{k-m}{k} H_{k n}(v)
\end{gathered}
$$


And after taking the $(n-1)$ root and rearranging:

$$
W_{j n}(b)=\frac{(k-m) H_{k n}(v)}{(k-m) H_{k n}(v)-k v_{j n}} \frac{v_{j n}-\sqrt[n-1]{b}}{\sqrt[n-1]{b}}
$$

Finally translating this back to the $c d f$ we get the desired results.

Proof of Proposition 3. As usual we know that for the type 1 firms in equilibrium we have $\Pi_{1}\left(b \rightarrow V_{1}\right)=\cdots=\Pi_{k}\left(b \rightarrow V_{k}\right)=$ Const, which implies for all the type 1 firms that,

$$
V_{j}\left(1-q_{j}\right)^{n_{1}-1}\left(1-s_{j}\right)^{n_{2}}=\text { Const }=Z_{1}
$$

While for all the type 2 firms we have that,

$$
V_{j}\left(1-q_{j}\right)^{n_{1}}\left(1-s_{j}\right)^{n_{2}-1}=\text { Const }=Z_{2}
$$

Dividing the equations above for the two types of firms and then summing over all the $k$ projects we get the identity:

$$
\left(k-m_{2}\right) Z_{2}=\left(k-m_{1}\right) Z_{1}
$$

Now since $m_{1}>m_{2}$, we have $Z_{1}>Z_{2}$. This gives us the first result that the firms that bid on more projects make higher equilibrium profits. Substituting $1-s_{j}=\frac{Z_{1}}{Z_{2}}\left(1-q_{j}\right)$ back to equations (1) we get $\left(n=n_{1}+n_{2}\right)$

$$
V_{j}\left(1-q_{j}\right)^{n-1}\left(\frac{k-m_{2}}{k-m_{1}}\right)^{n_{2}}=Z_{1}
$$

Taking $(n-1)^{t h}$ root and denoting $\beta=\left(\frac{k-m_{2}}{k-m_{1}}\right)^{\frac{n_{2}}{n-1}}$ we get,

$$
v_{j}\left(1-q_{j}\right) \beta=z_{1}
$$

Summing the above equation up over all projects finally yields $\beta\left(k-\sum_{j=1}^{k} q_{j}\right)=z_{1} \sum_{j=1}^{k} \frac{1}{v_{j n}}$ or,

$$
z_{1}=\beta \frac{k-m_{1}}{k} H_{k n}(v)=\left(k-m_{2}\right)^{\frac{n_{2}}{n-1}}\left(k-m_{1}\right)^{\frac{n_{1}-1}{n-1}} \frac{H_{k n}(v)}{k}
$$

The expected profit is $Z_{1}=\left(k-m_{2}\right)^{n_{2}}\left(k-m_{1}\right)^{n_{1}-1}\left(\frac{H_{k}}{k}\right)^{n-1}$. We can now find the individual probabilities from the equation $v_{j}\left(1-q_{j}\right) \beta=\beta \frac{k-m_{1}}{k} H_{k n}(v)$ which implies $q_{j}=1-\frac{\left(k-m_{1}\right) H_{k n}(v)}{k v_{j n}}$.

Similarly we can solve for the $s_{j}$ 's by substituting $\left(1-q_{j}\right)=\frac{Z_{2}}{Z_{1}}\left(1-s_{j}\right)$ into equations (2) getting

$$
V_{j}\left(1-s_{j}\right)^{n-1}\left(\frac{k-m_{1}}{k-m_{2}}\right)^{n_{1}}=Z_{2}
$$


Define $\gamma=\left(\frac{k-m_{1}}{k-m_{2}}\right)^{\frac{n_{1}}{n-1}}$ to get $z_{2}=\gamma \frac{k-m_{2}}{k} H_{k n}(v)$. And the expected profit is $Z_{2}=\left(k-m_{2}\right)^{n_{2}-1}\left(k-m_{1}\right)^{n_{1}}\left(\frac{H_{k n}(v)}{k}\right)^{n-1}$. The probabilities are given by $s_{j}=1-\frac{\left(k-m_{2}\right) H_{n}}{k v_{j n}}$.

We now turn to the final part of the proposition, namely deriving the bid distribution functions. We write the implicit equations (for the two types of firms):

$$
\begin{aligned}
& b\left(q_{j} W_{j}(b)+\left(1-q_{j}\right)\right)^{n_{1}-1}\left(s_{j} U_{j}(b)+\left(1-s_{j}\right)\right)^{n_{2}}=Z_{1} \\
& b\left(q_{j} W_{j}(b)+\left(1-q_{j}\right)\right)^{n_{1}}\left(s_{j} U_{j}(b)+\left(1-s_{j}\right)\right)^{n_{2}-1}=Z_{2}
\end{aligned}
$$

Dividing the equations yields

$$
\frac{s_{j} U_{j}(b)+\left(1-s_{j}\right)}{q_{j} W_{j}(b)+\left(1-q_{j}\right)}=\frac{Z_{1}}{Z_{2}}=\frac{k-m_{2}}{k-m_{1}}
$$

Substituting back we get

$$
b\left(q_{j} W_{j}(b)+\left(1-q_{j}\right)\right)^{n-1}\left(\frac{k-m_{2}}{k-m_{1}}\right)^{n_{2}}=Z_{1}
$$

From which we get,

$$
\sqrt[n-1]{b}\left(q_{j} W_{j}(b)+\left(1-q_{j}\right)\right) \beta=\beta \frac{k-m_{1}}{k} H_{k n}(v)
$$

And the function is as in Proposition 2 before $W_{j n}(b)=\frac{\left(k-m_{1}\right) H_{k n}(v)}{\left(k-m_{1}\right) H-k v_{j n}} \frac{v_{j n}-\sqrt[n-1]{b}}{\sqrt[n-1]{b}}$. Similarly we get $U_{j n}(b)=\frac{\left(k-m_{2}\right) H_{k n}(v)}{\left(k-m_{2}\right) H_{k n}(v)-k v_{j n}} \frac{v_{j n}-\sqrt[n-1]{b}}{\sqrt[n-1]{b}}$. But this applies only for the part of the distribution where both firm types bid with positive probability. Since $Z_{1}>Z_{2}$ type 1 firms must have a lower support for their equilibrium bidding strategies. Hence, the above $U_{j n}(b)$ distributions are applicable only for $b \geq\left(\left(k-m_{2}\right) \frac{H_{n}}{k}\right)^{n-1}=L_{2}$ which is the lower bound of the type 2 distribution. Clearly the lower bound of the type 1 firms is $Z_{1}$ because if they bid it they win for sure. Note that as expected $Z_{1}=\left(k-m_{2}\right)^{n_{2}}\left(k-m_{1}\right)^{n_{1}-1}\left(\frac{H_{k n}(v)}{k}\right)^{n-1}<\left(\left(k-m_{2}\right) \frac{H_{k n}(v)}{k}\right)^{n-1}$ since $m_{1}>m_{2}$. Therefore, the bid function between $Z_{1}$ and $L_{2}$ is calculated in the following way:

$$
b\left(q_{j} W_{j}(b)+\left(1-q_{j}\right)\right)^{n_{1}-1}=Z_{1}=\left(k-m_{2}\right)^{n_{2}}\left(k-m_{1}\right)^{n_{1}-1}\left(\frac{H_{k n}(v)}{k}\right)^{n-1}
$$

Taking roots and substituting the values for $q$ yields:

$$
\begin{aligned}
& \sqrt[n_{1}-1]{b}\left(\left(1-\frac{\left(k-m_{1}\right) H_{k n}(v)}{k v}\right) W_{j}(b)+\frac{\left(k-m_{1}\right) H_{k n}(v)}{k v}\right) \\
& =\left(k-m_{1}\right)\left(\frac{H_{k n}(v)}{k}\right)\left(\left(k-m_{2}\right)^{\frac{n_{2}}{n_{1}-1}}\left(\frac{H_{k n}(v)}{k}\right)^{\frac{n_{2}}{n_{1}-1}}\right)
\end{aligned}
$$


Let $\rho=\left(\left(k-m_{2}\right)\left(\frac{H_{k n}(v)}{k}\right)\right)^{\frac{n_{2}}{n_{1}-1}}$ and solve for $W_{j}(b)$ to get

$$
W_{j}(b)=\frac{\left(k-m_{1}\right) H_{k n}(v)}{\left(k-m_{1}\right) H_{k n}(v)-k v_{j n}} \frac{\rho v_{j n}-\sqrt[n_{1}-1]{b}}{\sqrt[n_{1}-1]{b}}
$$

Next we need to make sure that at the lower bound of the type 2 firms' distribution the two $W$ functions coincide. In other words, we need to show that for $b=\left(\left(k-m_{2}\right) \frac{H_{n}}{k}\right)^{n-1}$ which can be verified by direct comparison. Finally the full c.d.f functions (the complements of $W_{j}(b)$ and $U_{j}(b)$ ) are calculated and given in the Proposition.

Proof of Proposition 4. Let $r_{j n}$ be the probability that one of the $(n-2)$ symmetric firms will bid on project $j=1,2$. Let $W_{j n}(b)=1-G_{j n}(b)$ be the probability that one of those firms bids more than $b$ on project $j=1,2$. Let $\alpha_{i}$ be the probability that committed firm $i$ bids exactly $V_{i}$ on the high value project, with probability $\left(1-\alpha_{i}\right)$ firm $i$ bids according to the cdf function $\widetilde{G}_{i}(b)$ with $\widetilde{W}_{i}(b)=1-\widetilde{G}_{i}(b)$ being the probability of firm $i$ bidding above $b$ for $b<V_{i}$. The profit of each of the $(n-2)$ firm when bidding $b$ on project $j=1,2$ is given by

$$
\Pi_{j}(b)=b\left(r_{j n} W_{2 n}(b)+\left(1-r_{j n}\right)\right)^{n-3}\left(\alpha_{j}+\left(1-\alpha_{j}\right) \widetilde{W}_{j}(b)\right)
$$

In other words, the firms need to consider only the pricing of the other $(n-3)$ firms plus the single firm committed to the project they are bidding on. Specifically a firm would win the project if all the other $(n-3)$ firms either bid above $b$, or bid on the other project and furthermore, if the firm committed to the project needs to price higher than the focal firm.

If firm $i=1,2$ bids exactly $b=V_{i}$ it will win the project only if it is the only firm bidding on it. Firm $i$ 's expected profit is thus

$$
\widetilde{\Pi}_{i}\left(b=V_{i}\right)=V_{i}\left(1-r_{i n}\right)^{n-2}
$$

When firm $i$ bids $b<V_{i}$ its profits are given by

$$
\widetilde{\Pi}_{i}\left(b<V_{i}\right)=b\left(r_{i n} W_{i n}(b)+\left(1-r_{i n}\right)\right)^{n-2}
$$

We will first show that the strategies described in the Proposition indeed constitute an equilibrium and later we will show that no other $(n-2)-$ symmetric equilibrium exists. Firm $i=1,2$ will use a mixed strategy only if $\widetilde{\Pi}_{i}(b)=$ Const for every $b$ in the support of the equilibrium. Similarly for the other firms we must have for $\Pi_{1}(b)=\Pi_{2}(b)=$ Const for every $b$. Using the boundary 
conditions $\Pi_{1}\left(b \rightarrow V_{1}\right)=\Pi_{2}\left(b \rightarrow V_{2}\right)=$ Const gives the following equations

$$
V_{1}\left(1-r_{1 n}\right)^{n-3} \alpha_{1}=V_{2}\left(1-r_{2 n}\right)^{n-3} \alpha_{2}
$$

Let $\alpha_{j}=r_{(3-j) n}$ then solving for the probability from the above equation yields $r_{j n}=\frac{w_{j n}}{w_{1 n}+w_{2 n}}$ where $w_{j n}=\sqrt[n-2]{V j}$. In this case the lower bound of the price distributions for all the firms when bidding on project $i$ is the same. Hence $Y_{n}=V_{j}\left(\frac{w_{(3-j) n}}{w_{1 n}+w_{2 n}}\right)^{n-2}=\left(\frac{w_{1 n} w_{2 n}}{w_{1 n}+w_{2 n}}\right)^{n-2}$. Furthermore, all firms including the committed ones use the exact same distribution when bidding on the respective projects specifically:

$$
\begin{aligned}
& W_{2}(b)=1-\frac{v_{1 n}+v_{2 n}}{v_{2 n}}+\frac{v_{1 n}}{\sqrt[n-1]{b}} \\
& W_{j}(b)=\widetilde{W}_{j}(b)=1-\frac{w_{1 n}+w_{2 n}}{w_{j n}}+\frac{w_{(3-j) n}}{\sqrt[n-2]{b}}
\end{aligned}
$$

Finally translating back to the $c d f$ we get the desired results.

We still need to show that no other $(n-2)$ - symmetric equilibrium exists. This is done by showing that for any other potential symmetric equilibrium if the lower bounds of the bidding distributions are different for the committed firms and the switching firms then one of the committed firms can benefit by lowering its bid a bit. ${ }^{2}$

Proof of Proposition 5. Let $q$ be the probability of bidding on project 1 and let $W_{1}(b)$ be the cumulative probability of a firm bidding above $b$ conditional on bidding on project 1 . On project 2 , let $u_{\text {low }}(b)$ be the probability of bidding between $b$ and $L$ conditional on bidding below $L$, and let $u_{\text {high }}(b)$ be the probability of bidding between $b$ and $H$ conditional on bidding above $L$. Also define $\alpha$ as the unconditional probability of bidding above $L$. The profits from bidding $b$ on project 1 are given by:

$$
\pi_{1}(b)=b\left(q W_{1}(b)+(1-q)\right)^{n-1}
$$

For project 2: if $b \leq L$

$$
\pi_{2}(b)=b\left((1-q)\left((1-\alpha) u_{\text {low }}(b)+\alpha\right)+q\right)^{n-1}
$$

Note that $(1-\alpha) u_{\text {low }}(b)$ is the probability of bidding below $L$ but above $b$.

\footnotetext{
${ }^{2}$ The complete proof is standard but tedious and is available from the authors upon request.
} 
if $L<b \leq H$

$$
\pi_{2}(b)=\beta b\left((1-q) \alpha u_{h i g h}(b)+q\right)^{n-1}
$$

Now let us look at the limits of the bidding distribution

$$
\begin{aligned}
& \pi_{1}\left(b=V_{1}\right)=V_{1}(1-q)^{n-1} \\
& \pi_{1}(b=Z)=Z \\
& \pi_{2}(b=H)=\beta H q^{n-1} \\
& \pi_{2}(b=L)=L((1-q) \alpha+q)^{n-1}
\end{aligned}
$$

From the fact that each bidder has to be indifferent between his strategies we get $V_{1}(1-q)^{n-1}=$ $\beta H q^{n-1}$. As before define $v_{1}=\sqrt[n-1]{V_{1}}, l=\sqrt[n-1]{L}, h=\sqrt[n-1]{H}$ and $\gamma=\sqrt[n-1]{\beta}$ to get that $v_{1}(1-q)=\gamma h q$. From this the solution for the equilibrium probability of bidding on project 1 is given by $q=\frac{v_{1}}{v_{1}+\gamma h}$, which in turn determines $Z$ to be $Z=V_{1}\left(\frac{\gamma h}{v_{1}+\gamma h}\right)^{n-1}$ and $z=\sqrt[n-1]{Z}=\frac{\gamma h v_{1}}{v_{1}+\gamma h}$.

Observe that if $Z>L$ the bidders will use the same equilibrium as before with projects valuations of $V_{1}$ and $\beta H$. Therefore, consider for the rest of the analysis that $Z<L$ or $\frac{\gamma h v_{1}}{v_{1}+\gamma h}<l$. Solving for $\alpha$ we get $\alpha=v_{1} \frac{\gamma h-l}{l \gamma h}$. Using the fact that $\frac{\gamma h v_{1}}{v_{1}+\gamma h}<l$ we show that $\alpha=v_{1} \frac{\gamma h-l}{l \gamma h}<\frac{l\left(v_{1}+\gamma h\right)-l v_{1}}{l \gamma h}=1$ as is required for it to be an unconditional probability.

To complete the solution we need to find $T$ the lower bound for $u_{h i g h}$ which we find from the following equation:

$$
\beta T((1-q) \alpha+q)^{n-1}=L((1-q) \alpha+q)^{n-1}
$$

or $\beta T=L$. Therefore for the equilibrium to exist we need $\beta H>L$. Otherwise the equilibrium is one in which firms will ignore the higher valuation $H$ and will consider only $L$ and all firms will bid only up to a maximum of $L$. Finally we need to derive the cumulative bidding functions:

$$
W_{1}(b)=\gamma h\left(\frac{1}{\sqrt[n-1]{b}}-\frac{1}{v_{1}}\right) \quad \text { for } \quad Z \leq b \leq V_{1}
$$

For the second project we get

$$
u_{h i g h}(b)=\frac{v_{1}}{\gamma h}\left(\frac{h}{\sqrt[n-1]{b}}-1\right) \quad \text { for } \quad L / \beta \leq b \leq H
$$

Similarly for $u_{\text {low }}$ :

$$
u_{\text {low }}(b)=\frac{v_{1}}{l}\left(\frac{l}{\sqrt[n-1]{b}}-\frac{l}{\gamma h}\right) \quad \text { for } \quad Z \leq b \leq L
$$

Finally combining $u_{h i g h}(b)$ and $u_{l o w}(b)$ to a single function $W_{2}(b)$ we get the desired results. 
Prof of Proposition 6. Consider first the special case of increasing uncertainty by increasing $H$ while keeping $L$ constant. Specifically, assume that the second project valuation could be either $H_{1}$ with probability $\beta_{1}$ or $L$ with probability $\left(1-\beta_{1}\right)$ where $H_{1}>H$ and $\beta_{1}<\beta$, such that $\beta H+(1-\beta) L=\beta_{1} H_{1}+\left(1-\beta_{1}\right) L$. So we are considering an uncertain project with the same mean as before but with larger variance. Note that $\beta_{1} H_{1}=\beta H-\left(\beta-\beta_{1}\right) L<\beta H$. We need to consider 3 cases:

1. If both $\beta_{1} H_{1}$ and $\beta H$ are less than $L$ then the situation is identical to the one before and the expected bidder profit under both cases is $Z_{n}\left(V_{1}, L\right)$.

2. If $\beta H>L>\beta_{1} H_{1}$ the expected profit for the bidders in the new case is $Z_{n}\left(V_{1}, L\right)$ while in the earlier case their expected profit was $Z_{n}\left(V_{1}, \beta H\right)$. Since $\beta H>L$ the latter profit is higher.

3. $\beta H>\beta_{1} H_{1}>L$ the expected profit for the bidders in the new case is $Z_{n}\left(V_{1}, \beta_{1} H_{1}\right)$ while in the earlier case their expected profit was $Z_{n}\left(V_{1}, \beta H\right)$. Since $\beta H>\beta_{1} H_{1}$ the latter profit is higher.

In a similar manner we can show that every increase in uncertainty that preserves the mean valuation of the project reduces the expected bidder profit 